\title{
THE ROLE OF HORIZON-CONSCIOUSNESS IN FILMIC EXPERIENCES
}

HANNA GONÇALVES TRINDADE

\begin{abstract}
To understand the structure of our originary film experience, Husserlian phenomenology provides fundamental insights, for in his writings Husserl speaks of the notion of horizon to express the unthematized aspects of our experience of the world and its objects. According to the philosopher, we are implicitly familiar with the world and this familiarity allows us to always know in advance the world we experience. Consequently, and in a similar way, in the filmic experience, we could also speak of a "horizontal framework" which would allow us precisely to be first acquainted with the structure of our encounter with the film and thus to have an implicit pre-knowledge of how to behave towards this "object". Our objective in this paper is therefore to analyze how the internal structure of the films creates an original (affective) experience for the viewer to subsequently investigate the structure of this receptivity by the viewer.
\end{abstract}

\section{Introduction}

Since very early in his writings, Edmund Husserl recognized that in every apprehension of an object there are aspects which are not directly grasped, but that constitute nevertheless our experience of this object. For example, when consciousness is intuitively aware of any object in the foreground, it is simultaneously aware, although non-thematically, of the background as well. This implicit awareness not only accompanies, but more importantly determines the manner in which we perceive the object in the foreground, as we shall see. The background, like many other elements, is part of what Husserl calls horizon (der Horizont), i.e. those aspects of the experience of a thing that are not given in its apprehension

https://doi.org/10.14712/24646504.2019.8

(C) 2019 The Author. This is an open-access article distributed under the terms of the Creative Commons Attribution License (http://creativecommons.org/licenses/by/4.0). 
itself, but that are rather open possibilities offered by this apprehension, which can be explored through further acts. ${ }^{1}$

In filmic experiences this consciousness of the non-thematic is particularly important. While watching a film what is aimed is certainly the film projected in front of us. But this intuition is accompanied by a non-explicit awareness of all the background aspects that are co-given and that are affecting us, enabling the whole experience of "watching a film". Part of movie experiences, for example, is the implicit awareness of not being physically in the space of the film, but rather seated on a chair in a movie theater. As a consequence, as involved as we may be by the plot, there is a level of our consciousness that keeps us at distance, because we know this is all just a representation on a bi-dimensional screen. This consciousness is provided by what Husserl calls "horizon-consciousness", i.e. by the implicit awareness of these further aspects of our experience. We could therefore affirm that there are horizons that constitute our originary experience of a film such as it is.

Since Husserl's investigation of the horizon-consciousness describes how this implicit awareness of the world is constituted, an analysis of cinematographic experience from this point of view could help us understand how the originary experience of films is constituted. The aim of this article is therefore neither to analyze how a predicative knowledge is born out of films (i.e. how we judge or evaluate a film), nor to take into account each structure that compose our experience of films (i.e. the images, the movement, the temporality and the sense), but to simply focus in understanding the horizontal dimension of the process of apprehending "films".2 To that intent, we will in a first part describe Husserl's

1 As Dermot Moran explains "When I see a pen, I also, in that very act, see it as something which could be handled, which could be picked up. I grasp its graspability, as it were. Various 'horizontal' layers of reference are contained in the very experience itself - and of course they can be either confirmed or denied in subsequent experiences: for example, if I seek to pick up the pen and find it is glued to the desk. The horizon then maps out a set of expectations, and seeks confirmations or discontinuations consistent with the original given in the experience. If I pick up an apple, I have the expectation that I can bite into it. This is discontinued if it is a wax apple in a waxworks museum" (Moran Dermot, Introduction to Phenomenology, Routledge, 2002, p. 162).

2 Although many theorists have already dealt with this subject, their perspectives are often employed in favor of a particular approach regarding what a filmic experience should be - they are, thus, often normative. This paper, contrarily, intends to analyze the structure of every sort of filmic experience, regardless of its diverse forms of expression, hence the use of a Husserlian approach. We will make use in this paper of a wide range of theorists of diverse historical periods and cultural backgrounds - from the Hungarian formalist Béla Balazs in the 30s to the French realist André Bazin in the 60s. This happens precisely because the eidetic aspect of a Husserlian approach allows us to take into consideration a multitude of aspects at stake in the filmic experience, acknowledging their respective values, without, nevertheless, imposing how this experience should be, but rather analyzing the structure that already is in place in every instance 
notion of horizon so that in a second part we can apply this concept to our specific filmic experience.

\section{The notion of Horizont in Erfahrung und Urteil ${ }^{3}$}

According to Husserl, before any experience takes place, the object of our experience is not given as a completely empty substratum, but we already have a certain indeterminate familiarity with it. This pre-given dimension of our experience is what Husserl calls horizon: "One could say that the horizon embraces what one is conscious of in a non-thematic way. Itself remaining non-thematic, the horizon keeps the space open for the emergence of each and every theme"4. Since horizon is a characteristic of the relation between consciousness and the objects in the world, we will speak in a more general way of horizons as being of the experience. However, because every experience comprehends both the world with its objects and a consciousness that grasps them, the general notion of horizon will also include within itself different types of horizons, i.e. different non-thematic aspects of our experience, which vary according to which part of this correlation we focus.

The first of these aspects is certainly the world itself, which is already there for us before any experience takes place, pre-given in a simple certitude of belief. Since the beginning it affects us in the background of our consciousness and it is only

3 The first signs of the emergence of the idea of Horizon in Husserl's phenomenology can be found in Ideas I (1913) where, when describing the way the world appears in natural attitude, he affirms: "What is now perceived and what is more or less clearly co-present and determinate are penetrated and surrounded by and obscurely intended to horizon of indeterminate actuality (dunkel bewußte Horizont unbestimmter Wirklichkeit)" (Husserl E., Ideas pertaining to pure phenomenology and to a phenomenological philosophy, First Book, The Haguen Martinus Nijhof Publishers, 1983, \$27, p. 52). In these early writings, though, the analysis of the horizon was not Husserl's main concern, he doesn't go much further in his analysis of this pregiveness, as he takes this donation as an explicit thesis. But if initially phenomenology aimed at putting the world in parenthesis to analyze the structures of pure subjectivity, latter phenomenology seeks to understand how subjectivity operates in its apprehension of the world as pregiven. Thus, in works like The Crisis (1936) the phenomenological method appears as an instrument to return to the life-world and the question that is asked concern the "how" of the pregiveness of the world ("dem Wie der Vorgegebenheit der Welt": Husserl E., The Crisis of European Sciences and Transcendental Phenomenology, Evanston, Northwestern University Press, 1970, \$43). This investigation is born of a troubling but simple unsolved question until then: how can consciousness be aware of what is non-thematic? Husserl became thus more and more concerned to clarify precisely the manner in which the horizons of our experience overlap and interrelate so that they produce our originary experience of a world as such. Thus, a more clear answer to these problems will only appear years later in 1939 with the publication of Experience and Judgment by Landgrebe.

4 Geniusas Saulius, The Origins of the Horizon in Husserl's Phenomenology, Springer, 2012, p. 7. 
afterwards, through an awake interest, that we actually grasp them and an activity of knowledge is produced. The name for this universal ground of world-belief is horizon:

The being of the world in totality is that which is not first the result of an activity of judgment but which forms the presuppositions of all judgement [...] Therefore, all existents which affect us do so on the ground of the world; they give themselves to us as existents presumed as such, and the activity of cognition, of judgement aims at examining whether they are truly such as they give themselves to be, as they are presumed in advance to be, whether they are truly of such and such nature. The world as the existent world is the universal passive pregivenness of all judicative activity, of all engagement of theoretical interest. $^{5}$

As we can notice, Husserl marks a distinction between the world and the objects that constitute it, in the sense that the former is a horizon itself through which the latter can appear. This happens because the manner in which we are conscious of the world is different from the manner in which we are conscious of the objects that compose it, and yet both consciousnesses are connected: things can only appear in the world due to the world's performance as its pre-given background - and for this reason there is always an implicit consciousness of the world as the horizon - in the same manner that the world can only appear as an universal horizon through our apprehension of the objects in it: "each [thing] is something, 'something of' the world of which we are constantly conscious as a horizon. On the other hand, we are conscious of this horizon only as a horizon for existing objects; without particular objects of consciousness it cannot be actual"6. We can, thus, speak of two different types of interconnected horizons of our experience: the world as horizon and the horizons through which objects can appear, and our investigation of the one will be necessarily intertwined with the investigation of the other, as Saulius Geniusas explains:

If the world as horizon is a horizon for existent objects, then the phenomenological description of the manner of givenness of existent objects must disclose how they necessarily emerge from within a more rudimentary pregivenness of the world. Otherwise put, the world as horizon can be rendered thematic by way of disclosing how it

5 Husserl E., Experience and Judgment. Investigations in a Genealogy of Logics, London, Routledge and Kegan Paul, 1973, \$7, pp. 30/31.

6 Husserl E., The Crisis of European Sciences and Transcendental Phenomenology, op. cit., p. 143. 
forms a necessary counterpart to the appearance of existent objects so that without it, the appearance of objects would not be possible. ${ }^{7}$

As a consequence, a horizon-consciousness is described by Husserl as the "horizon of typical pre-acquaintance in which every object is given" 8 . In other words, there is an anticipatory framework for consciousness in which each object appears and it is only on the basis of it that a future knowledge of an object can be attained. This framework comprehends, thus, both the world itself as universal horizon and the horizons of the object's donation through which I can experience it.

Regarding the world-as-horizon, we find a pre-given ground which is not however empty, but full of an undetermined pre-knowledge, for the world offer us a series of beings known in general, but yet unknown in what regards their individual particularities. Our confidence in that which this horizon presents us is what makes the world familiar to us and what justify our belief in its existence. This pre-given world, always already known with certain familiarity, is the Lebenswelt, "the world in which we always already live, and that constitutes the ground of every operation of knowledge and every scientific determination"9. Our knowledge of the world is preceded by its pregiveness, by our familiarity with it, because the life-world is already impregnated by previous activities of knowledge that deposit their result there. Thus, we receive a world already laid out by others (education, traditions, cultures, religions, history, etc.). In other words, the sense of what is pre-given to us is already determined by the achievements of the sciences. For this reason we often display a prior conviction that the objects of our experience are indeed determined in themselves and what we do through experience would be nothing more than legitimate these determinations that exist in themselves in things. This means that our experience of things in the world is since the beginning mediated by an idealization that establishes in advance for us how to interpret it. But this idealization, carried out mainly by the natural sciences, produces nothing more than a predictable world that fits their specific ideas and methods, and yet we take these intuitions for granted and as ultimate truth. What phenomenology seeks is precisely not to accept a world previously determined in itself, but to understand the prior pregiveness of this life-world, "If, therefore, we wish to return to experience in the ultimately original sense which is the object of our inquiry, then it can only be to the original experience of the life-world, an experience still unacquainted with any of these idealizations but whose necessary foundations it

\footnotetext{
Geniusas S., The Origins of the Horizon in Husserl'sPhenomenology, op. cit., p. 182.

Husserl E., Experience and Judgment. Investigations in a Genealogy of Logics, op. cit., $\$ 33$, p. 150.

Ibid., $\$ 11$, p. 48 .
} 
is"10. For this reason we need to return to a pre-predicative experience, i.e. to this originary experience of a familiar donation of things: we need to analyze the horizons that structure our experiences in the first place.

If we now direct ourselves to this field of originary experiences, we can notice that it is not yet a field of objectivities in the proper sense, because the "I" has not attributed any definite sense to the objects. As a matter of fact, strictly speaking, at this level consciousness has not accomplished any objectifying activity. What we find is a passive pregiveness, which is not nevertheless a chaos, but simply a tangle of data structured in an undetermined and general way. These data are already the product of a type of constitutive synthesis of an inferior degree, since even at this passive level, where an attentive activity has not taken place yet, consciousness is already receiving information from its environment. This information is already being processed by consciousness through the immanent time-consciousness, even though the product of this synthesis has a simple general form of the object. This happens because time-consciousness is, for Husserl, the originary source of constitution of any type of identity, even of an inferior and general degree. At this passive level, time places the objects of my field of perception in the unity of the living present (lebendige Gegenwart) of my consciousness. But how does this passive pregiveness of the world as horizon allow me to grasp an object appearing in this sphere? The law that allows horizons to manifest is the association or what Husserl calls synthesis of recovery. It is an immanent connection that enables consciousness to affirm: "this reminds me of that" or "this sends me back to that". The associative genesis is the phenomenon that rules the sphere of passive pregiveness, since at this level it is only through this type of connection that we are able to move from one grasping to another (whether in a same object or from one object to another), creating thus a unity of experience.

It is worth nothing that this passage can be produced through two types of horizons: an internal and an external. The internal horizon concerns an intentionality that aims by anticipation at possible determinations of the object, it goes beyond the core of information that my current and immediate consciousness grasps by producing an anticipation regarding the next adumbrations (Abschattungen) I might have of this same object. Husserl often gives us the example of a red spherical object and as my perception goes along and I rotate this object, my internal horizon anticipates that I might continue to see a round and red object. But my apprehension of this spherical object is also accompanied by other objects that are simultaneously co-given with it in my field of perception. My external horizon

$10 \quad$ Ibid., $\$ 10$, p. 39. 
is the one responsible for grasping this background that surrounds every object to which I am currently paying attention and at every moment I can deliberately choose to turn myself to any of these other co-appearances.

Thus, the passive sphere is regulated by an associative structure that articulates all the singularities that are given to us, creating a structured field of giveness. Association is, consequently, what makes it possible for us to already be familiar with the object before even starting to actively grasp it, since through it consciousness is always linking one horizon to another in such a manner that the pregiveness of the life-world becomes already passively structured and so do the objects that appear in it. These passive syntheses of recovery have nevertheless an affective force: they produce a stimulation on the "I" that makes it orient itself to them. The action that is the product of this stimulation is not yet an actual activity of constitution of the "I", but it is rather and awakening of consciousness:

If the ego yields to the stimulus, a new element enters. The stimulus exercised by the intentional object in its directedness toward the ego attracts the latter more or less forcefully, and the ego yields to it. A graduated tendency links the phenomena, a tendency of the intentional object to pass from a position in the background of the ego to on confronting the ego. This is a transformation which, correlatively, is a transformation of the entire intentional background-experience (Hintergrunderlebnis) into one of the foreground: the ego turns toward the object. ${ }^{11}$

The combination between an affection suffered and a resulting awakening leads consciousness to look at something, making thus the background alive: objects approach me or get further away; they appear and disappear from my field of perception, "Insofar as in this turning-toward the ego receives what is pregiven to it through the affecting stimulus, we can speak here of the receptivity of the ego" 12 . When receptive, the "I" consents to what affects it and it embraces it. Therefore, we should not place this receptivity as opposed to activity, on the contrary this receptivity is an inferior degree of activity in the sense that my consciousness is not any longer just passively absorbing general forms of unity, but I am actually turning-towards that which is affecting me, even though I am not yet actively forming judgments and constituting definite senses.

Once consciousness turns itself to the object, horizons are awakened:

$11 \quad$ Ibid., $\$ 17$, p. 77.

12 Ibid., $\$ 17$, p. 79. 
Thus if I see the front of the motionless thing-like object, I am conscious, within the horizon, of the back of the object, which I do not see. The tendency which aims at the object then is directed toward making it equally accessible from the other side. It is only with this enrichment of the given, with the penetration into particularities and the being given "from all sides", that the tendency passes from the initial mode of aiming at something into the mode of attainment, a mode which has its own different degrees: imperfect attainments, partial, with components of unfulfilled aim". ${ }^{13}$.

In this sense consciousness becomes interested, it is motivated to discover more about the object (and its entourage) in such a way that new horizons repeatedly appear and consequently so do new possibilities. Therefore, our apprehension of the object becomes enriched and its sense becomes each time more precise, as we approach its ipseity. The positive feeling of satisfaction that accompanies this enrichment is what Husserl calls interest (Interesse). It is the act of getting closer to this object that is affecting me. This enrichment, in its turn, is only possible because consciousness develops intentions of anticipation: in the progression in the gasping of the object, protentional anticipations are created concerning what will come next. For example when grasping a face of a cube, I tend to anticipate how the back of the cube, which I do not see at this moment, will look like. It is in the progressive striving from one mode of giveness of the object to the next that a certitude regarding the existence of this object is produced, gradually as my intentions get fulfilled. Nonetheless, it is also due to this anticipation that deceptions can happen whenever there are impediments or frustrations of my intentions. This is why our initial certitude can be altered into modes of negation or doubt.

In either case, if at first, at a passive level, we had a mere general familiarity with the object, the more we become interested in it (the more it affects us), the more we want to fulfill this general form with specific determinations. This means that when we become interested, we're already leaving the domain of pure receptivity and orienting ourselves to the object: it is a passage. If initially this interest appears under the form of a simple contemplative intuition, soon enough our interest assumes a new shape: we want to explicate the object. That means that when we merely contemplate an object, we grasp it as a whole, in its vague generality. We already develop intentions of anticipation regarding it, but we only apprehend it in general, since we have not followed any horizons yet. Once the contemplation becomes explication though, "we strive to explain all that it 'is', what it manifests of itself as regards internal determinations, to enter into its content, to grasp it in its parts and moments, and to enter anew into these by taking them separately and

13 Ibid., $\$ 19$, p. 82/83. 
letting them display themselves", all of this without losing sight of the object as a whole. Thus, "the explication is penetration of the internal horizon of the object by the direction of perceptual interest" 14 .

Taking into consideration the characterization of the horizon we have presented so far, we could say that the horizons set an indeterminate determinability; i.e. the apparition of the Lebenswelt is not only a product of the permanent fulfillment of anticipations, but it can also include situations of frustration which modify the previous configuration of sense we projected. Thus our initial horizon of typical pre-acquaintance is defining, yet not definite, "what affect us is known in advance at least insofar as it is in general a something with determinations; we are conscious of it in the empty form of determinability, that is, it is equipped with an empty horizon of determinations" 15 . The incessant modifications that the horizon can undergo show us that if on one side the horizontal framework of our experiences is a condition of possibility for the apparition of the world, providing further (internal and external) determinations to it, on the other side this framework is determined by these apparitions that compose horizon itself. There is, therefore, a codetermination of appearances and horizon-consciousness:

Not only because the horizons are motivated by appearances in their emergence, but also because appearances in their duration continue to compel horizon-consciousness to obtain and exert new kinds of anticipatory projections. The horizons determine appearances as appearances of a particular objectivity; yet it is appearances themselves that motivate the horizons to schematize them in a called-for manner. For instance, so as to perceive a deck of cards on the table as cards and not as boxes of matches, consciousness must be guided by the awakened horizons of anticipation. Yet it is the appearing phenomenon in its duration that motivates consciousness to hold on to the projected configuration of sense; and when appearances frustrate the projected configuration, the horizons undergo a modification: what earlier showed itself as a deck of cards now proves to be a box of matches. Due to such a codetermination, the horizons reveal themselves not only in terms of their formal structure, but also as concrete projections of sense, which call for the object to manifest itself in an anticipated way. ${ }^{16}$

14 Ibid., $\$ 22$, p. 105 .

15 Ibid., $\$ 8$, pp. $37 / 38$.

16 Geniusas S., The Origins of the Horizon in Husserl's Phenomenology, op. cit., p. 102. 


\section{The horizon in filmic experiences}

How can the idea of horizon help us understand the experience of films? To answer this question we need firstly to understand how such an "object" is structured, for the manner in which films are internally organized sets up mechanisms that enable the viewers to be integrated in the experience, allowing them to be first of all affected by the film, before effectively producing predicative judgments, as we shall see. We will analyze the structure of receptivity of the film by the viewer in the next paragraphs, but to understand this structure it is important to firstly investigate how this affectivity is created by the own means of production of the film.

One of these mechanisms is the "shock-effect" of the montage. Technically montage consists in the juxtaposition of shots in order to create a sense that is born from their relation. The discovery, highlighted by Koulechov's experience, that the manner in which images are connected can create cognitive changes in the spectator is what gives to montage not only the power to show something, but to express it. As Sergei Eisenstein notices, this effect is not a monopoly of cinema, but just a natural consequence of such occurrence:

[...] any two sequences, when juxtaposed, inevitably combine into another concept which arises from that juxtaposition as something qualitatively new. This is by no means a purely cinematic phenomenon, but one which inevitably accompanies the juxtaposition of two events, two facts, two objects. We are almost automatically prone to draw a quite specific, conventional conclusion whenever certain discrete objects are placed side by side before us. ${ }^{17}$

What montage does is, therefore, to juxtapose images in order to create a sensitive stimulus in the spectator. This stimulus is supposed to remind the viewer of an effect felt before, regarding other lived experiences. In other words, through the shock, montage subtly plays with our capacity to associate certain relations between images to certain reactions (that can be merely cognitive, but also emotional). This associative dimension of the montage is what allows it to affect us directly, for this association is spontaneously awakened in the spectator. ${ }^{18}$ Eisenstein

\footnotetext{
Eisenstein Sergei, "Montage 1938" in Glenny Michael, Taylor Richard (ed.), Towards a Theory of Montage, vol. 2, New York, IB Tauris, 2010, pp. 296/297.

18 This passive dimension would explain the possibility in cinema of a "reception in distraction", as Walter Benjamin calls: "Reception in a state of distraction, which is increasing noticeably in all fields of art and is symptomatic of profound changes in apperception, finds in the film its true means of exercise. The film with its shock effect meets this mode of reception halfway. The film makes the cult alue recede into the background not only by putting the public in the position of the critic, but also
} 
was the first to put in practice this characteristic in a methodical manner, since he realized that the sheer effect of "shock" could affect the spectator naturally, for it plays with a passive dimension of his/her experience: 19 "It is a matter of simply profiting of the knowledge of the world that one may necessarily suppose on the viewer and to play in the editing with this implicit knowledge" 20 . It is not the technique of montage itself, though, which is apprehended passively; on the contrary, although fragmentation is part of the manner in which the world appears to us (through profiles), when we live our ordinary lives, we neglect this fact, since the synthetic structure of our apprehension of the world gives us a homogeneous and fluid experience of life. The discontinuity of montage seems to us, thus, incompatible with our natural way of living and films oblige us, in this sense, to consciously face a fragmented reality, ${ }^{21}$ which goes against our natural attitude towards our own reality. But the associative dimension of montage encourages us to embrace these ruptures by identifying on their juxtaposition relations we might have experienced before.

This associative dimension is largely facilitated by the fact that shots, being the uninterrupted mobile take of an event, action or object, reproduce, to a certain extent, our own mundane perception. Although moving images are mere representations, and not the presence of an object, they present nevertheless a reproduction of the structure of our ordinary perception:

by the fact that at the movies this position requires no attention. The public is an examiner, but an absent-minded one" (Benjamin Walter, "The Work of Art in the Age of Mechanical Reproduction", in Illuminations, Translated by Harry Zohn, New York, Schocken Books, pp. 240/241), This happens because we are habituated with the manners in which films express their meanings, in such a way that, due to this familiarity, we can allow ourselves to be distracted.

Eisenstein saw in this "shock" between shots the capacity to guide the spectator intellectually. Because the juxtaposition of the montage seeks to reproduce associations of the mind of the spectators themselves, through montage the filmmaker could prepare and direct the associations awakened in the consciousness of the viewer, which would give him/her the capacity to perfectly control through montage the ideas arising on the viewer's mind. As a consequence, for Eisenstein the shock only had value as a mean for the spectator to access an idea or concept.

20 Aumont Jacques, Montage, "la seule invention au cinéma", Paris, Vrin, 2015, p. 42.

21 This is what Mitry explains in the following passage: "We know that our mind is capable of observing a same thing non-stop. The attention dilutes itself on the object, it blurs. And if, in everyday life, we have the impression of a "total", constant perception of the things that surround us, it is only because we are within a homogeneous continuum and that at any time we have the faculty to pay attention to any aspect of this environment [...] However, in montage, the discontinuity is more brutal than in reality where these moments of attention are always blended in a more or less vague whole. Here still, the filmic frame cuts the passage from one shot to the other in the sense that, precisely, it cuts the relations of the represented given with the whole from which he is subtracted" (Mitry Jean, Esthétique et psychologie du cinéma, Paris, Editions du Cerf, 2001, pp. 226/227). 
The spatial experience that we live in cinema can, firstly, be described as similar to the one we live in the context of normal perception, due to the strong impression of reality constitutive of the cinematographic spectacle. The latter relies on the photographic nature of the image, on the perceptive richness of the visual and sound material that it contains, on the acceptable illusion of three-dimensionality associated to its perceptive code. $^{22}$

In filmic experiences we find, thus, a perception reproduced in the film and a perception of the viewer of the film as an "object" appearing on screen, the paradox being that the latter relies on the viewer's apprehension of the former. As a consequence, the structure of our experience of films concerns not only our experience of it as an object that appears in a certain manner, i.e. as moving images, but also our apprehension of the experience that is reproduced in it as its content. In other words, to perceive a film is not only to perceive an "object" appearing to us on the screen, but because this object offers itself as a perception, we perceive a perception as well. ${ }^{23}$ Thus, realism inscribes itself in every shot not because of its power to record the real as it is, but mostly because of its capacity to partly reproduce the conditions of a real perception, i.e. its unilaterality (we can only see one angle at the time and there is no view from nowhere), subjectivity or multi-

22 Gaudin Antoine, L'espace cinématographique. Esthétique et Dramaturgie, Paris, Armand Colin, 2015, p. 55.

23 This distinction can be better understood within the framework of Husserl's phenomenology of image. To put it in simple terms, according to Husserl, in the apprehension of images there are three dimensions to be taken into consideration: the physical thing (the object upon which the image appears, in this case the screen); the image-object (the image itself, the representation) and the image-subject (what is represented). Because films are primarily images, the same distinction can be applied to them. In this sense, one can speak of different perceptions implicated in these different levels. The first is my ordinary perception which takes the film on the screen as a random object in my field of perception. The second is the perception of the image-object: as a fictum, the image gives itself as something perceptive, as a complex of sensations appearing on a screen. But precisely because it is a fictum, the image appeals to something else: the represented scene aka the image-subject. Since the latter is actually absent, we have to access it through imagination, the latter being thus born out of the perception of the representation. But this does not change the fact that the representation is made through a mime of the features of an ordinary perception, in such a way that what we see is a representation of a perception. We find here a third type of perception: the perception reproduced in the shot. In other words, we find in filmic experiences three types of perception: my ordinary perception of the screen (physical thing) which presents us the perceptive content of the film (image-object) which presents a "representation of an ordinary perception" (image-subject). Due to our limited number of pages and for the sake of clarity, here we will make no distinction between the first and second types of perception, since the perception through which we see the screen is, in practice, the same through which we see the images (the difference being that when perception is aimed at the representation, and not the screen, an imagination results from it, modifying this perception, but this is a subject for a further analysis). 
plicity of perspectives (each perception is a perspective of a subject from a specific standpoint) and the dynamics between what appears and what is hidden through movement (attested by the transitions between what is in-screen and off-screen). This is what Clélia Zernik calls a "perceptive realism" of the image, "That testifies of the impossibility of grasping the world without involving a look [...] rather than realism, we should speak of 'cinematographic perceptivism', a notion that would take into account the possibilities for cinema to reconnect with ordinary perception, precisely because it is always subjective and partial" 24 . Certainly, we have nevertheless no control of the perception reproduced in the shot on screen. Furthermore, the latter puts us at distance from the space in the film, circumscribing the world of the image, detaching it from our englobing environment and from our own bodies. And thirdly, the montage, being essentially a discontinuous process, creates ruptures in the homogenous perceptions reproduced in the shots, in such a way that these juxtapositions of random perceptions in the film does not seem to correspond to the ordinary manner in which we apprehend life, as we affirmed earlier. These differences between the perception in the film and our own marks the disjunction between the film's reality and our world and as a consequence, due to this double perception in the filmic experience, the relation between the viewer and the film becomes ambiguous: we find ourselves in the real space of our immediate field of perception, although we grasp a perception reproduced in a realistic manner. But in spite of this distinction, the reproductive character of the perception in the film invites us in every case to participate in its world, for we identify it as a possible manner to grasp our own world. In his writings André Bazin stresses precisely how the objectivity of the reproduction of (the perception of) the real in films is not incompatible with the subjective participation of the spectators, as we might expect. On the contrary, it is this realism that allows the establishment of a "solidarity between the spectator and the spectacle" 25 . In a passage of his text Lécole italienne Bazin shows us how, for instance, through a technique like the depth of field, Orson Welles succeeds in making the spectator interact with the space of the film in a manner similar to the way we grasp reality:

Orson Welles restituted to the cinematographic illusion a fundamental quality of the real: its continuity. The classic decoupage, deriving from Griffith, decomposed reality in successive shots that were not a sequel of points of view on the event, neither logic nor subjective ones [...] The decoupage introduced thus an evident abstraction in reality. While the lenses of the classic camera focus successively on different places of

24 Zernik Clélia, Perception-Cinéma. Les enjeux stylistiques d’un dispositif, Paris, Vrin, 2010, p. 85.

25 Ibid., p. 84. 
the scene, the one of Orson Welles embraces with an equal sharpness the entire visual field which finds itself at the same time in the dramatic field. It is not the decoupage anymore who chooses for us what we see, conferring through it a meaning à priori, it is the mind of the viewer who is obliged to distinguish the dramatic spectrum particular to the scene [...] Thanks to the depth of field of the lenses, Orson Welles has restituted to reality its sensible continuity. ${ }^{26}$

Bazin notices that this reproduction of the structure of the relation between us and the world in the shot makes it easier for us to associate what we see on screen and what we live off-screen. ${ }^{27}$

In this regard, our analysis intersects Merleau-Ponty's vision on cinema. ${ }^{28}$ On one side, for the French philosopher film and phenomenology "share a certain way of being, a certain view of the world" 29 and this is his central thesis in what concerns cinema. But in spite of this common ground, Merleau-Ponty insists also on the fact that the film does not give itself in the same manner our reality does, and here a gap is dug between phenomenology, that describes our relation with the world, and the films, that show this relation but through expressive means

26 Bazin André, Qu'est-ce que le cinéma? Paris, Cerf, 2011, p. 271.

27 For Bazin, though, precisely to allow the spectator to enter easily in the film, the discontinuity of montage should be "forbidden", since it is only the shot that would have the capacity to reproduce the mobile and continuous perception we have of the real world. Bazin believed that the role of cinema was to reveal the real as it is, only an uninterrupted recording (the shot) could capture the essence of this reality, without deforming it through cuttings, as montage does it: "The ideal of the forbidden montage is the donation to the viewer of an untouched reality whose sense is not written anywhere in the image and that he/she will, therefore, work to discover or to invent it, by himself/ herself" (Aumont J., Montage, "la seule invention au cinema", op. cit., p. 55). If montage is forbidden (or, more exactly, reduced), then there would be no need to create sense through montage, since it would already appear on the screen. The real is what it is. The question is not to know what the sense of this reality is or if this real mean something, but since the film has to reproduce this reality, so it has to reproduce its enigmatic aspects as well. The "long take" would be, in this manner, a perfect example of a narrative structure that respects the real, for it does not impose on us what we need to focus. On the contrary, the camera flies above the recorded reality and shows the situation that develops, as and when it develops, without retouch.

Here we are strictly focusing on Merleau-Ponty's interpretation of cinema as presented around the 40s, mainly in the conference given at the IDHEC in Paris on the 13th March 1945 about the new psychology, i.e. the gestalt theory, and cinema. The transcript of the conference can be found in the collection Sense and Non-Sense under the title The Film and the New Psychology. However, the philosopher seems to revise his position regarding the concept of perception in later years, which can be found in the book Le Monde Sensible et le Monde de l'Expression, a collection of notes from his courses in the College de France in 1953.

29 Merleau-Ponty Maurice, Sense and Non-Sense, translated by Hubert L. Dreyfus and Patricia Allen Dreyfus, Northwestern University Press, 1964, p. 59. 
proper to its dispositive. ${ }^{30}$ As a consequence, the cinematographic perception differentiates itself from the natural one in many regards. As he notices, our natural perception depends on a subject's involvement in the world, involvement which is incarnated, but this corporal dimension is lacking in film's experiences, since the screen sets the world of the film apart from our bodies in the movie theater. Furthermore, different of the ordinary perception, the cinematographic perception is limited, for it has no horizons, as he affirms in Phénoménologie de la perception:

When, in a film, the camera is trained on an object and moves nearer to it to give a close-up view, we can remember that we are being shown the ash tray or an actor's hand, we do not actually identify it. This is because the screen has no horizons. In normal vision, on the other hand, I direct my gaze upon a sector of the landscape, which comes to life and is disclosed, while the other objects recede into the periphery and become dormant, while, however, not ceasing to be there. Now, with them, I have at my disposal their horizons, in which there is implied, as a marginal view, the object on which my eyes at present fall. The horizon, then, is what guarantees the identity of the object throughout the exploration; it is the correlative of the impending power which my gaze retains over the objects which it has just surveyed, and which it already has over the fresh details which it is about to discover. ${ }^{31}$

This confusing position of Merleau-Ponty regarding the relation between cinema and reality is the reason why, as Deleuze affirms, films become a sort of "ambiguous ally" 32 . On one side, films make us see a manner of being in the world, but on other side this manner of presenting the relation between man and world does not perfectly fulfill the conditions of our natural perception, as Deleuze explains: "As a result, cinematographic movement is both condemned as unfaithful to the conditions of perception and also exalted as the new story capable of "drawing close to" the perceived and the perceiver, the world and perception" 33 . Although, on one side, Merleau-Ponty takes the film both as an "object of perception" and an object that presents a perception, on the other side the philosopher's analysis does

30 In Merleau-Ponty's argumentation this distinction is mainly consequence of montage, that through its spatio-temporal discontinuity presents us a "form of expressivity absolutely specific" (Rodrigo Pierre, L'intentionnalité créatrice. Problèmes de phénoménologie et d'esthétique, Paris, Vrin, 2009, p. 251). Indeed, it is through montage that films give us a perception of the whole and not of the juxtaposed parts. This is reason why Gestalttheorie can be so fitting in the description of cinematographic perception, according to Merleau-Ponty.

31 Merleau-Ponty M., Phenomenology of Perception, Translated by Colin Smith, New York, Routledge, 2002, p. 78.

32 Deleuze Gilles, Cinema 1 The Movement-Image, Translated by Hugh Tomlinson and Barbara Habberjam, Minneapolis, University of Minnesota Press, 1986, p. 57.

33 Idem. 
not pay much attention to the distinction between these two types of perception. Merleau-Ponty does not highlight the fact that what he calls "cinematographic perception" can be divided between a reproduced perception in the film and an ordinary perception of the spectator of the film. In this sense, despite the resemblances between the perception in the film and our ordinary one, our perception of the film cannot indeed be equated to our natural perception and in this regard we do agree with Merleau-Ponty when he affirms: "That does not mean, however, that the movies are fated to let us see and hear what we would see and hear if we were present at the events being related" 34 . But this happens not because the perception in the film does not correspond perfectly to the ordinary one, but rather because the apprehension of the filmic space by the viewer cannot be equated to the limited apprehension of the camera of the space filmed. What we perceive is not only what the camera perceives - i.e. the reality as captured by the lenses - but above all we also see the specific manner in which the camera perceives this reality. In other words, the double perception produced in the grasping of the film allows us to have a perceptive experience of a perception:

The viewer does not see objects, neither what someone sees, but he/she sees see or rather perceives perception. In the redoubling the properly phenomenological dimension of cinema is at stake, which comes out of the transitivity to invent an intransivity where it is thus the conditions of perception that are given to be seen, the perceptive experience that is staged on a mode that makes it resemble a revelation. This redoubling itself of the perceiving indicates the qualitative and dense dimension of the perceptive experience, which does not rise from the direct see. When we watch the eyes of the young maid, what we see is not her eyes, but what is properly invisible, a particular qualitative lived experience. ${ }^{35}$

Therefore, although the perception in the film has limiting horizons - limited mainly by the frame - Merleau-Ponty neglect the horizon of the perception of the spectators themselves in the grasping of the "object-film" in the movie theater. ${ }^{36}$ The experience reproduced in the film might not fulfill the conditions of our natural perception and thus have no horizons, but our experience of films does. How do they emerge? Let us take a closer look at the structure of our filmic experience.

\footnotetext{
Merleau-Ponty M., Sense and Non-Sense, op. cit., p. 57.

Zernik C., Perception-Cinéma. Les enjeux stylistiques d’un dispositif, op. cit., p. 101.

6 For a deeper analysis on the types of perception implicated in filmic experiences, see the book Perception-Cinéma where Clélia Zernik draws a clear and profound distinction between the different types of perception in cinema, their functions, their relations and how their distinct uses in films differentiates, for example, Italian Neorealism from other types of cinema.
} 
First of all, the act of watching of a film was not always an ordinary activity. Cinema became familiar to us throughout its historical evolution, but the first cinematographic exhibitions had a great impact on the spectators, although they were merely a register of a moment in real life. Such is the case of Lumière Brothers' L'Arrivée d'un train à La Ciotat (1895) which depicts a situation as simple as the arrival of a train in a station. Interestingly enough, it is said that during its first exhibition the viewers actually ran away from the movie theater once they saw the train on the screen coming towards them. This accident can be explained by the fact that, at the time, viewers were not yet acquainted with this new type of object and did not know how to respond to such an unfamiliar experience. As cinema became popular and easily accessible, the spectator became increasingly used to the act of "watching a movie". Part of the acquaintance with this experience was, naturally, a matter of habit enabled through education, in such a way that when we go to a movie theater, we already implicitly know how this experience will unfold. We do not expect, for instance, that the train appearing on the screen reaches us, for it is not "there". But the development of such habit was also largely facilitated by the own manner the cinematographic dispositive was structured, as we saw above. Despite the specificities of the medium, there are also aspects of it that allows us to recognize in the structure of the apparition of the framed world a similarity to the manner our own world appears, making it easier for us to accept what we see in the specific way we see it. In the following passage Bazin highlights, for instance, the "natural" aspect of montage: "[...] montage in its original naivety is not perceived as an artifice" 37 . If, on one side, films present a form of expression that does not completely correspond to our usual manner of grasping reality - mainly due to the manner in which the framing arbitrarily cuts the real, the shot expresses movement without however moving our bodies and the montage assimilates discontinuous blocks of space and time - on the other side, its own structures guarantee that this expression keeps a "real" aspect. Therefore, we find in the development of the filmic experience a sort of dynamics between (a) the development of a habit with the emergence of a new sensibility on the side of the viewer and (b) a progressive manipulation of the apparatus in order to give it a greater capacity of expression of the real (above all with the advent of sound and color), making possible the establishment of a familiarity between the spectator and the filmic experience. This familiarity enabled filmic expression to become common for us, in such a way that whenever we encounter certain structures of narration, we implicitly suppose

37 Bazin A., Qu’est-ce que le cinéma?, op. cit., p. 54. 
what they express. ${ }^{38}$ This evolution resulted, for instance, in the implementation of standard types of editing, since the public became gradually familiar with the logic behind customary forms of concatenation. Thus, we learned the laws that rule this experience and we became habituated to it: "The forms of expression of the silent cinema have progressively and rapidly developed and they have created on the public the faculty of comprehending this new form of language. We did not only see the birth of a new art, but we also saw the birth of a man that disposed of a new sensibility, of a new talent, of a new culture" 39 .

Therefore, whenever watching a film, there is a primary level of passivity involved in our apprehension in the sense that we are pre-acquainted with this type of object and, because of this familiarity, in an early stage the filmic experience is already previously structured in an undetermined way. The object "film" is already known in general, but yet unknown in what concerns the individual particularities of this specific film we may be watching. Thus, in the same manner that the apprehension of objects in our life-world is wrapped in a horizon of typical pre-acquaintance, so is the apprehension of films, for we are familiar in advance with the form of this type of experience. We could therefore call filmic horizon our pre-acquaintance with films, i.e. the implicit familiarity of our consciousness with the structure of filmic experiences which defines the manner we behave regarding films. We implicitly know, for instance, that time passes differently in the film, that actions taking place in it cannot hurt us directly, etc. It is through this acquaintance that the film as a specific type of objectivity can appear to us. This means that, as it happens regarding any object, also regarding the filmic horizon we can identify both and internal and external horizons. The filmic internal horizon concerns the determinations internal to the "object" film, i.e. the manner its content appears: its scenes framed from certain angles, shot in certain ways and arranged through montage to create a certain sense. As we saw, there are aspects in the manner these structures are composed that enable us to passively grasp this internal horizon with familiarity and thus to facilitate our apprehension of it. But our experience of films comprises not only the apprehension of its content, but also a perception

38 This is the case of what we call "over-the-shoulder shot", for example. In this type of shot we may find two characters engaged in a conversation, but to show how each character reacts, shots from both perspectives of both characters are interchanged. Objectively nothing assures us with absolute certainty that one person is talking to the other, but we infer that a conversation is happening between the two characters. The over-the-shoulder shot is just one of the many types of techniques we find in films which we became accustomed with, whenever such compositions are used, we are already familiar with it and know what to expect next.

39 Balazs Béla, Le cinéma. Nature et évolution d’un art nouveau, Paris, Petite Bibliothèque Payot, 2011, p. 31. 
of the film as an "object" on the screen, which is consequently accompanied by what is given simultaneously in our current field of perception. The filmic external horizon is the one responsible for making us always aware of the background of wherever we are having the experience of watching the film. For this reason, we can at any moment choose to pay attention to a person making noise next to us in the movie theater or yet notice a glare on the television where the movie is projected. Due to the external horizon, our participation in the world of the film is always limited, for this implicit awareness of our real external background always forces us to acknowledge that it is "just a movie" on a screen, we are not effectively there. Thus, both internal and external horizons define the manner in which we experience films, as both participation and distance.

As with the objects of our life-world, this familiarity with films is also first of all produced through association. Films present in this regard a particularity, because although films are above all "objects", one cannot ignore the fact that such "objects" have the particularity of presenting themselves as a world of their own, as a visual expression of life itself, as Andrei Tarkovski affirms on his book Sculpting in Time: "I see in the chronic, the record of facts in time, as the essence of cinema: for me, it is not a matter of a way of filming, but of a way of reconstructing, of recreating life" 40 . Whether by documenting a situation in real life, by representing a fictional story or by creating a complex imaginary reality, cinema attempts in every case to recreate the structure of human experiences. It is precisely what our analysis of techniques like the montage and the shot showed us above - they both partly reproduce the manner in which we grasp the world, the first by awakening our mundane associations and the second by reproducing the configuration of our perceptive apprehension. Consequently, patterns or situations depicted on the film will always remind us of previous Erlebnisse, which contribute for the film to become a familiar object: we are pre-acquainted with the things we see on the screen because they appear in a manner similar to the donation of our Lebenswelt outside the movie theater. Therefore, when we affirm that we are pre-acquainted with the structure of films, it means that we are not only familiar with the general structure of film (i.e. both internal and external horizons) but also with the structure of its own content (i.e. life itself). For this reason the life-world appears as a horizon for filmic experiences in a double sense: not only because, as an "object", the apparition of the film, like any other object, relies on the pre-given background of the life-world, but also because films partly reproduce internally the structure of the apparition of this life-world and consequently it is only through our implicit

40 Tarkovski Andrei, Esculpir o Tempo, São Paulo, Martins Fontes, 2010, p. 73 (my translation). 
consciousness of the world itself that associations can be made and the film can be grasped. The synthesis of recovery is precisely the one responsible for making us "assimilate filmic relations to relations of real facts, the visual scheme being understood as a repetition of known or experienced schemes, even if it is artificially fabricated" 41 . Therefore, a film is a priori passively structured not only because the structure of the experience of this object is known in general in advance, but also due to the similarity of the structure of the donation of its content with the general form of donation of our own Lebenswelt.

Furthermore, it is also through association that we can link our current experience of a movie with past cinematographic experiences and therefore to have an anticipatory framework regarding films. This is precisely what enables the viewer to create expectations: on the basis of previous filmic experiences, we can anticipate the types of relation one can establish between images, in such a way that we can anticipate the shot that follows or even expect where the narrative is heading to. Such anticipatory framework is precisely what makes a film surprise us, and most of the time that is exactly what the film director looks for, "the perceptive anticipation has to be thwarted by the author in order for the surprise to constantly arouse the attention of the spectator" 42 . The aim is to interfere with our anticipations, obliging the viewer to be constantly engaged in the act of watching. The filmmaker plays with the fact that we want to fulfill our empty anticipatory intentions, even if that means that we might have to rearrange our initial anticipations or to even deny them, the entire idea of the thriller genre in cinema is based in the manipulation of these anticipations.

It is through the breaking of anticipatory patterns that films exercise stimulation. On one side the film director tries to find ways to affect the viewer, techniques like the close-up or the subjective shot are there precisely to help the audience to identify ${ }^{43}$ themselves to the situations and characters, making it easier for us to feel affected by the images. The stronger this affection is suffered, the more the viewer wants to participate and enrich his/her apprehension of the film. This stimulation awakens new horizons, the background becomes alive: we take notice of situations, of objects on the screen and we become eager for the film to increasingly gain precision. Most of the time, this affectivity ultimately amounts to consent from our

\footnotetext{
Mitry J., Esthétique et psychologie du cinéma, op. cit., p. 232.

Ibid., 230.

43 The concept of identification can be misleading, since to identify does not necessarily mean "to share their feelings". The notion we aim at, thus, is rather this capacity of participation in the space of the film. It is a matter of "being-with" the characters and not of "being in their place" as Antoine Gaudin affirms in his book L'Espace Cinématographique and Noel Carroll explains in his book The Philosophy of Motion Pictures.
} 
part in receiving and embracing this information: if initially they were taken for granted by us in their passive pregiveness, now we become interested in them. That means that the viewer has an "aspiration to penetrate the film", as Husserl would say, caused by the stimuli the director creates, and this immersion gives the spectators a progressive positive feeling of satisfaction as they follow this affectivity. Consequently, the interest awakes in the viewer an urge to explicate what they are apprehending: we do not want to take the film as a general whole, but we want to penetrate its content, grasp each shot attentively, or, in phenomenological words, we seek to unfold all the internal determinations of the film, and as this internal horizon of the film is explored, the external one tends to be neglected.

\section{Conclusion}

The first conclusion we can draw from this analysis is that the notion of horizon helps us realize that there is a co-determination between the filmic horizon and the spectator's individual experiences. Our pre-acquaintance with the filmic experience is what allow us to grasp film in its objectivity: we are familiar with its structure, so we know how to relate to this specific type of object. But each film transforms our anticipatory framework; it transforms the horizons through which we will grasp films in future experiences. We might, for example, anticipate the story differently or we might take interest in different details. For this reason, films from directors like Jean-Luc Godard or Robert Bresson might be initially disturbing, since they subvert the classic structure we find in most films (the first through an inconstancy in the rhythm, the second through the refusal in using professional actors), disrupting our common anticipatory scheme. This happens because each cinematographic experience becomes sedimented in our consciousness in such a way that in the next experience, we can associate the new filmic experience with these sediments and therefore anticipate the structure, projecting thus a sense to our current experience. When this structure is altered, we are left with not much with which to associate the current experience and it becomes difficult to fulfill our anticipatory intentions. But this brand new and different filmic experience will be added to our collection of sediments, changing the filmic horizon we had previously:

Artworks can create new conventions. A highly innovative work can at first seem odd because it refuses to conform to the norms we expect. But closer look may show that an unusual artwork has its own rules, creating an unorthodox formal system, which 
we can learn to recognize and respond to. Eventually, the new systems offered by such unusual works may themselves furnish conventions and thus create new expectations. ${ }^{44}$

Therefore, our pre-acquaintance with the filmic horizon might determinate how to perceive a film, but this horizon is, in its turn, constantly changing.

The consideration of this dynamics between the filmic horizons and the viewer's consciousness enables us to see the spectator in a new way. The filmic experience is not a rigid relationship between a viewer and an object of art completely closed in itself. On the contrary, it is a dynamic process that depends both on the pre-acquaintance of the spectator with the structure of films, but also on the projection of sense from the spectator that is invited to take part in the film. This happens because, as with the life-world, the horizon of filmic experiences is also characterized by an indeterminate determinability, i.e. our pre-acquaintance with the structure of films defines the manner we experience it, but the fact that each specific experience depends on our own projection of sense opens the possibility for us to constantly interfere in this experience itself and for this reason it is never a definite experience. As a matter of fact, it is precisely this horizontal determinability of our apprehension of films that does not keep us apart from the film in a position of sheer contemplation. This happens because the passivity generated both by the structure of the film itself - mainly through the associative dimension of montage, by the perceptive reproduction of the shot and the mechanical recording of the framing - and by our habit with the form of this experience, allow us to easily adhere to the film and thus to be affected in a more profound manner, because we are distracted. But this participation implies that the sense of the film is not something imposed on us, on the contrary we are invited to project a sense based on the associations the film offers us, as Clélia Zenirk notices: "Firstly, films are not instrumentalized, they do not want to say something by themselves, they don't have an autonomous sense [...] The perceived world, as in ordinary perception, challenges the viewer, needs his/her commitment to make sense" 45 . However, contrary to Zernik that only see in genres like the Neorealism the potentiality to invite the spectators to project their sense, we have tried to argue that such participation is part of every filmic experience and this is due to the spectator horizon-consciousness that activates his/her associative structure in every case. ${ }^{46}$

44 Bordwell David, Thompson Kristin, Film Art: An Introduction. 5th edition, The McGraw-Hill Companies Inc, 1979, p. 71.

45 Zernik C., Perception-Cinéma, op. cit., p. 87.

46 Certainly, representational films and realist one differ in many regards, such as the manner the space is explored and the degree of immersion of the spectator, but in every case a sort of participation is 
This interweaving between a pre-acquainted film and a participative viewer allows the filmic experience to be in constant evolution, since film and spectator are persistently transforming the filmic experience's horizons and with it the future of an entire art.

Hanna Trindade is a former student of the program Erasmus Mundus EuroPhilosophie and has just completed her Ph.D. at the Faculty of Human Sciences of the Charles University with a thesis entitled Le vécu du cinema: Une approche husserlienne de l'expérience filmique. She is the author of a chapter entitled "The lived experience of motion pictures" in the book Philosophy and Film: Bridging Divides.

E-mail: hanna_trindade@hotmail.com

always in place, for we are never indifferent to what we experience and a projection of sense is always produced. 